\title{
Revelando Fatos, Sentidos, Afetos e Providências sobre o Trote em uma Faculdade de Medicina: Narrativa de uma Experiência
}

\author{
Revealingfacts, Senses, Affections and \\ Actions of the "Hazing" in a Medical School: \\ a Narrative of Experience
}

\author{
Marco Akerman, \\ Silmara Conchão, \\ Roberta Cristina Boaretto, \\ Fernando Luis Affonso Fonseca, \\ Maria Aparecida Pinhal
}

\section{PALAVRAS-CHAVE \\ - Educação Médica; \\ - Violência; \\ - Prevenção e Controle}

\section{KEYWORDS}

- Medical Education;

- Violence;

- Prevention and control.

Recebido em: 25/03/2012

Encaminhado: 03/05/2012

Aprovado em: 11/05/2012

\section{RESUMO}

O presente artigo narra um conjunto de fatos relacionados à recepção aos calouros de um curso de medicina, indica as mudanças que foram adotadas para a recepção dos ingressantes no ano seguinte e apresenta os resultados obtidos com essas intervenções. O desafio presente durante todo o trabalho foi fazer com que os incidentes ocorridos durante a recepção aos calouros não se repetissem mais. Muita discussão e muito diálogo precederam a formulação do plano de ação. Como pressuposto básico, defendeu-se a ideia de que a diretoria da faculdade em questão tinha de liderar esse processo e que a tarefa de receber o calouro não era atribuição exclusiva do veterano, e sim de toda a comunidade acadêmica, sob a tutelada Diretoria. Ainda não se pode afirmar que a cultura que permeia o trote foi modificada, mas é possível identificar sinais e indícios de que houve melhora importante na relação entre os estudantes da faculdade no processo de recepção aos novos estudantes que ingressaram no curso de medicina.

\section{ABSTRACT}

This article recounts a series of events related to the reception of the school-freshmen in a Medical School and indicates what changes have been adopted for the reception of new students in the following year, and the results obtained with these interventions. The challenge was rather that the whole thing would not be repeated again. Much discussion and a lot of dialogue preceding the formulation of action plan. The basic premise was the idea that the School Board had to lead this process and that the "freshman" does not "belong to the veteran", but it was the responsibility of the whole community of scholars, under the baton of the Board. It is not possible yet to assure that the hazing culture has been modified, we can identify signs and evidence that there was significant improvement in the relationship between students in the School regarding the reception of the new students. 


\section{INTRODUÇÃO}

Dicionários da língua portuguesa definem trote como "andadura natural das cavalgaduras, entre o passo ordinário e o galope". Pode significar também "zombaria realizada por pessoa que, pelo telefone, se faz passar por outra, ou não diz seu nome". E, mais recentemente, pode indicar prova a que, nas escolas e universidades, os veteranos (estudantes mais antigos) submetem os calouros (estudantes recém-chegados). Portanto, trote, inicialmente, trata do caminhar de um animal e depois foi sendo utilizado também como palavra para expressar "zombarias, provas". Como é possível associar o trote com os princípios da educação superior, que tem como um de seus objetivos a garantia da liberdade de expressão e da liberdade de caminhar dos indivíduos que participam dessa comunidade?

Parece que trote não combina com o caminhar livre, garantido pela Constituição brasileira, no artigo $5^{\circ}$, inciso XV. Sob a égide da busca da autonomia de sujeitos que precisam fazer escolhas livres de pressões está embasado o presente artigo.

"Sejam bem-vindos à Faculdade!". Com essas palavras estavam sendo recebidos os pais dos novos estudantes dos cursos de medicina, enfermagem, ciências farmacêuticas, fisioterapia, terapia ocupacional, nutrição e saúde ambientalda instituição observada.

Dentre os vários interesses manifestados pelos pais, um deles era sobre o trote imposto aos calouros de medicina. Os pais foram tranquilizados com um leque de informações dadas por professores e estudantes de que havia sim um "ritual de passagem, mas que isso não passava de um conjunto de atividades para que o calouro se integrasse na Faculdade".

Em uma roda de conversa com veteranos da Faculdade, percebeu-se, inicialmente, que o objetivo maior desse "ritual" seria formar um espírito de corpo entre os estudantes e que esse "ritual de passagem" teria entre suas funções "baixar a bola do calouro que entra na Faculdade se achando" por ter passado em um curso tão cobiçado. Nesse sentido, estaria a lógica do calouro "baixar a cabeça", de ser chamado apenas de calouro no início das aulas para depois adquirir um apelido e de "servir" ao veterano lhe trazendo bebidas em festa, por exemplo.

Infelizmente, fatos ocorridos após essa reunião não puderam validar a tranquilidade que foi passada aos pais pela Diretoria da Faculdade de que seus filhos estariam "sãos e salvos" ao serem recebidos como calouros.

Portanto, o presente artigo narra um conjunto de fatos ocorridos relacionados à recepção dos calouros de um curso de medicina e indica que mudanças foram adotadas para a recepção dos ingressantes no ano seguinte e os resultados obtidos com essas intervenções.
Esta narrativa é parte da pesquisa "Bulindo com a Universidade: um estudo sobre o trote na medicina", coordenada por Marco Akerman, Silmara Conchão e Roberta Boaretto, aprovada pelo Comitê de Ética em Pesquisa da Faculdade (registrada sob o número 194/2010) e financiada com recursos para bolsas de iniciação científica providos pelo Centro de Estudos de Saúde Coletiva da Faculdade.

\section{Caminhos Metodológicos}

Os autores desta narrativa, mais do que pesquisadores, foram, juntos com os estudantes, protagonistas de uma sucessão de fatos, que merecem ser trazidos à luz.

O artigo levanta hipóteses sobre como esse processo de recepção, mais que um "ritual de passagem", se revela como um modo de relação entre estudantes ao longo do curso de medicina.

Intimidações, abusos e assimetrias de poder entre estudantes não se restringem ao período de recepção ao calouro, conhecido como trote. São atos que persistem ao longo do ano, fazendo imaginar que o bullying (atitudes agressivas, intencionais e repetidas que ocorrem sem motivação evidente e adotadas por um ou mais estudantes contra outro(s), causando dor e angústia, e executadas dentro de uma relação desigual de poder) descrito e relatado no ensino fundamental e médio está também presente no ensino universitário ${ }^{1}$.

Portanto, o trote tem sido um instrumento significativo para justificar e perpetrar o bullying na faculdade, onde há a clara distinção entre "o mais forte" e "o mais fraco". Tais práticas são sustentadas socialmente e provocadoras de silêncio, solidão e medo, que mobilizam diferentemente rapazes e moças.

A metodologia utilizada para a elaboração do presente artigo é a técnica da narrativa, que tem como objetivo mostrar que "a experiência, dimensão existencial do viver, pode ser abordada e compreendida utilizando relato dos fatos, acontecimentos e afetos. Cabe ao pesquisador colocar-se, então, mais como um recolhedor da experiência, inspirado pela vontade de compreender, do que como um analisador à cata de explicações"2,3.

A seguir, narra-se uma sucessão "dos fatos, acontecimentos e afetos", bem como as providências que foram tomadas para enfrentar o problema.

\section{Narrativa dos Acontecimentos}

Contexto

No início do ano letivo, a faculdade onde se deu este estudo, por meio de sua ouvidoria e de sua Comissão de Apoio Permanente aos Estudantes, recebeu uma série de denúncias, tanto anônimas quanto identificadas, por telefone ou por e-mail, relatando a existência de atos de violência contra calouros do curso de medicina. 
Essa Comissão de Apoio, de caráter permanente, substituiu a Comissão de Recepção ao Calouro, de caráter provisório, por compreender que muitas das situações vividas pelos calouros na recepção se mantinham de maneira velada ao longo do ano.

Nenhuma das denúncias chegou à esfera policial, pois não foram abertos Boletins de Ocorrência, apesar de haver no site da faculdade uma mensagem sugerindo essa atitude.

No entanto, estudantes citados nas denúncias foram chamados individualmente para averiguação, na presença de professores e estudantes membros da comissão. Todos os estudantes negaram seu envolvimento em atos de violência. As iniciativas da comissão e o teor das denúncias foram relatados em reuniões aos estudantes do $1^{\circ}$ ano do curso de medicina, ao Núcleo Docente Estruturante e à Comissão de Residência Médica, que decidiram incluir em seus estatutos punições específicas para os residentes que fossem denunciados por ações abusivas e violentas.

\section{Novo Fato}

Apesar de toda a mobilização por parte da Comissão de Apoio, o vice-diretor da faculdade recebeu por e-mail uma denúncia anônima que declarava a ocorrência de "introdução de pimenta através do ânus" em calouros. A seguir, um trecho do texto:

"Eu sou mãe de um estudante do primeiro ano de medicina. Queria expressar meu desgosto por algumas coisas que vem acontecendo na faculdade. Eu vim no sábado... e disseram que os nossos filhos iriam ser muito bem recebidos e integrados à faculdade. Pois bem, isso não é o que vem ocorrendo, existe um trote violento sim, os calouros apanham no chamado 'educandário', que acontece no campo. Porém, além da agressão física, existe a introdução de pimenta no ânus dos calouros. Isso é uma boa recepção, não acha? Aliás todos serão colegas daqui a alguns anos e o que esperar desses futuros médicos formados por essa faculdade? Todas as quintas-feiras, alouns calouros selecionados pelos veteranos devem comparecer a esse educandário. Lá, veteranos... fazem a festa. Eu espero que o senhor, como vice-diretor da faculdade, tome alguma providência, e não adianta proibir festas dentro da faculdade ou ainda deixar calouros de um lado e veteranos do outro, o senhor deve tomar medidas mais drásticas, como, por exemplo, a punição dos agressores e a colocação de câmeras no tal campo, porém sem que eles saibam. Aí você terá provas concretas, porque eu já sei de várias denúncias que ocorreram e nada foi feito... Bom, espero que o senhor tome medidas cabíveis e não com toda faculdade, pois são alguns que praticam esse trote violento, e eu acho que já está na hora de acabar."

Diante desse fato, realizou-se reunião com todos os estudantes do $1^{\circ}$ ano de medicina, que confirmaram publicamente essa denúncia de "introdução de pimenta através do ânus" em calouros.
No sentido de se obter embasamento sólido e por escrito para uma tomada de decisão com precisão e critérios, todos os estudantes do $1^{\circ}$ ano do curso responderam, sem se identificarem, a um questionário elaborado pela Comissão de Apoio com seis perguntas:

(1) Você foi vítima de introdução de pimenta no ânus?

(2) Se sim, pode identificar quem realizou o ato?

(3) Você já foi vítima de alguma humilhação por parte de seus colegas de faculdade?

(4) Se sim, qual? Pode dizer quem realizou o ato?

(5) Você já presenciou algum colega seu sendo humilhado por outro colega?

(6) Se sim, qual? Pode identificar quem realizou o ato?

Cento e seis questionários foram respondidos, $65 \%$ dos estudantes informaram terem sido vítimas de algum tipo de humilhação por parte dos veteranos, tendo sido confirmada a denúncia de "introdução de pimenta no ânus".

Referendadas pela Diretoria e de acordo com o Regimento Interno, foram tomadas medidas disciplinares, de acordo com a intensidade e a frequência das denúncias.

\section{Desdobramentos}

A Congregação da Faculdade se reuniu e, por unanimidade - apoiada por abaixo-assinados dos estudantes exigindo providências firmes (72/106 estudantes do $1^{\circ}$ ano firmaram um abaixo-assinado e 150 estudantes dos outros 5 anos) - referendou as medidas tomadas anteriormente e determinou a abertura de processo disciplinar, recomendando que fossem ouvidos todos os estudantes do $1^{\circ}$ ano e os suspeitos de agressão por uma Comissão Independente. Foi solicitado que em 20 dias fosse apresentado relatório em reunião extraordinária da Congregação.

A Comissão de Averiguação cumpriu a seguinte metodologia de trabalho: (1) os estudantes do 1ano foram subdivididos em grupos de 20, de acordo com a ordem de chamada ( $\mathrm{N}=106$ estudantes); (2) os estudantes considerados como "envolvidos agressores", citados nos questionários anteriores,foram convocados por intermédio de carta contendo Aviso de Recebimento a comparecerem no dia agendado, às 14 horas, na sala predefinida ( $\mathrm{N}=15$ estudantes e um médico residente); (3) as datas de atendimento aos estudantes do $1^{\circ}$ ano foram feitas em seis dias consecutivos, no mesmo horário e local; (5) os encontros possuíam hora marcada somente para início, sendo livre o tempo de permanência do estudante com a comissão; (6) aos estudantes foi dada a possibilidade de conversarem com os membros da comissãoem grupo ou separadamente; (7) todos os estudantes assinaram um termo de 
consentimento e responderam a um questionário. Entrevistas autorizadas previamente pelos estudantes foram gravadas.

Foram sete dias de atendimento, em média 8 horas de trabalho por dia, $83 \%$ dos estudantes do $1^{9}$ ano deram seus depoimentos (89/106); 72\% responderam que haviatrote abusivo; $88 \%$ dos estudantes acusados como agressores atenderam à convocação da comissão (14/16); 100\% dos estudantes acusados negaram qualquer envolvimento com os atos citados; e as declarações foram realizadas na presença de advogados; todos os estudantes acusados eram, ou foram, membros da Atlética da Faculdade.

Os seguintes atos de violência foram relatados pelos estudantes do $1^{\circ}$ ano como "repertório" do trote:

1. Agressão física (fechar o indivíduo em caixa contendo gelo)

2. Agressão física (socos, pontapés, chave de braço, cuspe)

3. Agressão moral

4. Agressão verbal

5. Pressão psicológica

6. Humilhação

7. Ato da pimenta (cartão vermelho)

8. Mesa redonda (falar sobre a vida sexual)

9. Assédio moral

10. Coação

11. Educandário feminino

12. Obrigatoriedade em beber ("kosucos", "tequiralho")

13. Pagamento de "funça" (responder chamada para outro estudante, comprar bolo, pagar bebida, fazer trabalho).

Os depoimentos foram analisados e os atos acima descritos foram associados com cada estudante acusado como agressor. Foram atribuídos graus de gravidade (de 1 a 4 , sendo 1 para "menos grave" e 4, "mais grave"), de acordo com a quantidade e tipos das agressões sofridas. Dois estudantes tiveram grau 4, quatro estudantes grau 3, dois estudantes grau 2 e seis estudantes grau 1.

Esses resultados foram apresentados na Reunião Extraordinária da Congregação e foi determinada, por unanimidade (com abstenção dos estudantes), a expulsão da faculdade dos dois estudantes grau 4, a suspensão por 60 dias para os estudantes grau 3 e para os estudantes grau 2 e 1 foram reiteradas as repreensões e advertências anteriormente emitidas.

Um conjunto de medidas foi proposto:

- fechamento imediato do "campo" onde ocorreram os fatos descritos;
- reformulação no modo como as atividades da Atlética eram desenvolvidas;

- proibição de recados e informações dos veteranos em salas de aula sem acompanhamento ou autorização prévia - os estudantes relataram que esse era um momento de pressão psicológica e verbal intensa, quando os recados sobre treinos e competições eram repassados;

- fim da proibição, imposta pelos veteranos aos calouros, de frequentarem o restaurante da Faculdade — simbolicamente, a Diretoria da faculdade ofereceu um almoço no restaurante para todos os estudantes do $1^{\circ}$ ano.

As medidas foram inicialmente comunicadas aos estudantes punidos e seus familiares, que, em muitos casos, tiveram reação explosiva e de total incompreensão em relação aos motivos que levaram à punição de seus filhos, tendo sido comum a ocorrência, por parte dos estudantes, de declarações como: "Eu só fiz aquilo que fizeram, comigo quando aqui cheguei" ou "Só queria que os calouros se envolvessem com a faculdade como eu me envolvi". Posteriormente, todas as classes foram visitadas pessoalmente pela Diretoria e pela Comissão de Apoio aos Estudantes, que fizeram o relato de toda a intervenção empreendida e suas consequências.

Finalmente, os pais de todos os estudantes do $1^{\underline{0}}$ ano foram chamados para conhecerem os fatos e suas respectivas consequências. Nesse momento, chamou a atenção a fala de uma aluna que, reagindo a uma pergunta de um pai, perguntouse a Diretoria dava garantias de que nunca mais tais episódios voltariam a se repetir.

A aluna ainda comentou completando sua fala: "Confio que a Diretoria irá fazer tudo ao seu alcance para que isso não se repita, mas eu não tenho essa certeza, porque a cultura ao redor do trote é algo muito velado e eu não sei se esta cultura foi ou não abalada".

Depois de todos esses desdobramentos, seguiu-se uma intensa batalha jurídica entre a faculdade e os estudantes expulsos e suspensos. A Justiça, finalmente, ordenou em liminares a reintegração dos "expulsos" sob a alegação de que "não tiveram direito ao contraditório e à ampla defesa". O processo ainda tramita e foi aberto inquérito policial pela Secretaria de Segurança do Estado de São Paulo para apurar os fatos.

\section{Medidas Adotadas para o Ano Seguinte}

O desafio era que aquilo tudo não se repetisse novamente. Mas como fazer? Muita discussão e muito diálogo precederam a formulação do plano de ação. Como pressuposto básico estava a ideia de que a Diretoria da faculdade tinha que liderar este processo e que o "calouro" e "sua recepção" não "perten- 
ciam ao veterano", mas eram de responsabilidade de toda a comunidade acadêmica, sob a tutelada Diretoria ${ }^{4}$.

Um conjunto de medidas foi adotado. De alguma maneira, nesse momento, tem-se enfatizado o "vigiar e punir", mas sem que essa tática inicial signifique um fim em si mesmo. O propósito básico é a intervenção na cultura do trote, que transcende o âmbito da faculdade e perpassa, muitas vezes, as atitudes e procedimentos profissionais durante a carreira profissional.

Medidas de regulação, controle e punição são insuficientes para tanto. Um contínuo processo de diálogo, à luz de qualquer evento sobre o tema, com os órgãos colegiados, com as entidades estudantis, de residentes e de ex-alunos tem sido a tônica.

Que medidas de vigilância e controle foram essas?

1. Instalação de 25 câmeras no campus principal da faculdade, com capacidade de efetuar gravações durante 24 horas em locais estratégicos.

2. Por sugestão de um estudante, que também é advogado, foi elaborada uma cartilha intitulada Movimento trote já era, cabeça baixa nunca mais, que foi distribuída no primeiro dia de aula para todos os estudantes. Também, no primeiro dia de aula, o Promotor Público de Santo André fez uma palestra para todos os estudantes, mostrando seus direitos e deveres. Essa cartilha fazia uma relação entre os atos do trote e o seu enquadramento no Código Penal. A cartilha foi inspirada em um documento elaborado pelo Ministério Público do Estado de São Paulo, em 2010, e trazia a seguinte informação:

"A leitura desse documento trará aos novos calouros o conhecimento necessário para dizerem "NÃO" às práticas absurdas que constituem crime e esclarecerá aos veteranos as atitudes criminosas que, se cometidas, serão passíveis de ações administrativas (como suspensão ou expulsão), civis e criminais, sob pena inclusive de prisão. Importante lembrar que qualquer outra prática criminosa não mencionada nesta cartilha também estará sujeita às mesmas penalidades administrativas e às penas estipuladas no Código Penal. Lembrem-se que a Constituição Federal do Brasil estabelece que ninguém pode alegar a ignorância da Lei".

Exemplos de como se relacionou trote e Código Penal:

1. DOS CRIMES CONTRA A LIBERDADE E INTEGRIDADE INDIVIDUAIS

i) obrigar os calouros a ficarem de cabeça baixa (olhando para o chão) sempre que estiverem na presença de um veterano sob ameaça de agressão física;

ii) ditar normas de comportamento como obrigar as meninas a usarem cabelos presos, sem maquiagem ou unhas pintadas, sem brincos e saias;

iii) obrigar os calouros a tirarem seus calçados antes de entrarem na Atlética; iv) proibir que os calouros frequentem a lanchonete da faculdade;

v) obrigar os calouros a tomarem bebidas alcoólicas contra sua vontade.

As práticas elencadas do item i a v constituem os seguintes crimes:

Crime constrangimento ilegal - Art. 146 do Código Penal Pena: detenção de 3 (três) meses a 1 (um) ano.

Perigo para a vida ou saúde de outrem - Art. 132 do Código Penal - Pena: detenção de 3 (três) meses a 1 (um) ano.

vi) trancar os calouros em um local, mandar ficarem de joelhos desferindo-lhes socos e pontapés ou obrigá-los a se agredirem mutuamente;

vii) impedir que os calouros se retirem das festas da faculdade ou mesmo saiam da sala de aula enquanto os veteranos estão passando os "recados" da Atlética.

As práticas elencadas nos item vi e vii constituem os seguintes crimes:

Crime de sequestro e cárcere privado - Art. 148 do Código Penal - Pena: reclusão de 2 (dois) a 8 (oito) anos.

3. Qualquer contato de estudantes e ingressantes em sala de aula deveria ser autorizado previamente pela Coordenação de Curso e constar na grade de programação semanal, que foi postada no site durante o primeiro mês da recepção. Sempre que possível, esses contatos em sala de aula com os ingressantes era acompanhado por um docente ou um inspetor de estudantes.

4. Foram feitas gestões junto à mantenedora para incluir no seu orçamento o "apoio a atividades esportivas" de maneira que recursos contínuos fossem garantidos à Atlética da faculdade. Muito da pressão sobre os calouros se devia à necessidade de obter recursos para as competições promovidas pelos estudantes, sem o respectivo aporte financeiro garantido previamente.

Para além do controle e da vigilância, buscou-seconstruir novas formas de sociabilidade para receber os novos alunos.

Foi realizada uma oficina conjunta entre docentes e estudantes, em que estiveram presentes todas as entidades estudantis e projetos de extensão realizados por estudantes para organizar a recepção aos novos ingressantes. A premissa básica era que, na primeira semana, os ingressantes deveriam conhecer todas as frentes estudantis da Faculdade - DA, Atlética, Sorrir é Viver (grupo clown), Congresso Médico Universitário (congresso científico), IFMS (intercâmbio estudantil internacional), Feira de Saúde/DAP (extensão do DA), etc.- e não só ter contato com os veteranos e membros da Atlética, como acontecia em anos anteriores.

Esse conjunto de medidas adotadas anunciam, primeiramente, que a Direção de uma faculdade não pode ser omissa 
com a recepção de seus novos estudantes. Ela tem de deliberadamente operar as atividades dessa recepção, em conjunto com os estudantes, sob pena de que, ao não executar essa tarefa, passe a ideia aos estudantes de "vazio receptivo", lhes abrindo espaço para sua própria atuação autônoma.

Segundo: há de se explicitar interdições e limites: câmeras, cartilha, contatos com a promotoria criminal, etc.

Terceiro: mobilizar e ativar uma cultura da diversidade e do respeito, com a abertura de espaço de participação na recepção a todas as "áreas" estudantis. Em tempos passados, o DA se "atreveu" a oferecer uma "pizzada" para os novos estudantes, e a atividade foi coibida pelos veteranos, instando todos os ingressantes a se retirarem do DA, "pedido" prontamente atendido pelos novos estudantes. Aos Diretores do DA restaram algumas pizzas e a frustração de não ter podido ser parte da recepção aos novos colegas.

\section{Observações Preliminares}

O caminho é árduo, e os ganhos até o momento são frágeis, mas se destacam alguns avanços:

1. O jornal do Diretório Acadêmico da Faculdade, à época,trouxe como matéria de capa a recepção aos calouros e destacou o espaço dado a todas as entidades estudantis nessa recepção, valorizando a diversidade. Mais ainda, problematizou de maneira competente a tensão entre tradição e inovação, e concluiu que a "hibridação entre tradição e inovação é decerto muito preciosa e permite a evolução de fato".

2. Nos últimos três meses os estudantes seguiram uma tradição consagrada na faculdade, treinaram muito para a Calomed e foram os campeões.Duas mensagens de texto recebidas logo após essa vitória e que foram enviadas por dois estudantes talvez indiquem alguma inovação: (1) "professor, GANHAMOS A CALOMED!!! Acho que agora acredita-se que não precisa bater em ninguém para treinar..."; e (2) "Boa-noite, professor. Acabo de ser informado que os calouros se sagraram campeões da Calomed. Nada melhor para reforçar que não é pela força que as coisas acontecem. Estou muito feliz por mais esta conquista da 'nova' faculdade que estamos construindo!".

3. Mais ainda, em comparação com anos anteriores, a lista da medicina "girou menos", isto é, menor número de estudantes trocou a Faculdade de Medicina do ABC (FMABC) por outra faculdade em que também havia sido aprovado no vestibular.

4. No primeiro ano da intervenção, não houve nenhuma denúncia por parte de estudantes ou pais de violências ou abusos sofridos pelos ingressantes. Esse indicador de "denúncia zero" continuará sendo a meta para o futuro vindouro e um termômetro da ação. Entretanto, qualquer denúncia será trabalhada de maneira firme e coletiva, entendendo que o tempo de ação contínua é de no mínimo seis anos, quando a turma que foi recebida de maneira distinta pela comunidade acadêmica receberá o "seu calouro". Só aí, talvez, é que haverá ciência do impacto positivo na cultura do trote.

5. Constituição de um grupo de pesquisa sobre o trote universitário constituído por discentes e docentes e intercâmbio com outras universidades, com a realização de visitas e seminários conjuntos.

\section{AGRADECIMENTOS}

Seria injusto não mencionar o apoio incondicional de um conjunto de pessoas a este processo de intervenção sobre o trote: Raquel Ferrari, Marina Mendonça Paiva, Danilo Baltieri, Ethel Cheter, Maria Carolina Colombo, Deborah Lzeibel, Sergio Baldassim, Registila Beltrame, Ricardo Souto, Edson Fujiki, Nicolas Gomez, Ligia Reato, Maria Medeiros, Adilson Pires Casemiro. Um agradecimento especial a muitos estudantes e funcionários pela sincera colaboração.

\section{REFERÊNCIA}

1. Akerman M, Conchão S, Hotimsky S, Boaretto R. Violência e intimidação na recepção aos calouros nas faculdades de medicina: ato que persiste ao longo do ano. Rev Bras Educ Méd. 2010; 34(4): 627-628.

2. Dutra E. A narrativa como uma técnica de pesquisa fenomenológica. Estudos de Psicologia 2002; 7(2): 371-378.

3. Lira G, Catrib AMF, Nations MK. A narrativa na pesquisa social em saúde: perspectiva e método. Rev Bras de Promoção em Saúde 2003; 16(1-2): 59-66.

4. Almeida Junior AR, Queda O. Universidade, preconceito e trotes. São Paulo: Hucitec; 2006.

\section{CONTRIBUIÇÃO DOS AUTORES}

A narrativa é fruto do grupo de pesquisa composto por Marco Akerman, Silmara Conchão e Roberta Boaretto. Marco elaborou a primeira versão da narrativa e Silmara e Roberta contribuíram com as várias versões dela decorrentes. Fernando e Maria Aparecida elaboraram o material relacionado com os resultados obtidos pela Comissão de Averiguação e revisaram o manuscrito.

\section{ENDEREÇO PARA CORRESPONDÊNCIA}

Marco Akerman

Faculdade de Medicina do ABC.

Av. Príncipe de Gales, 821

Vila Príncipe de Gales — Santo André

CEP. 09060-650 SP 